\title{
BMJ Open Systematic investigation of childhood sleep-disordered breathing (SDB) in Beijing: validation of survey methodology
}

\author{
Xiaodan Li, ${ }^{1}$ Jun Tai, ${ }^{1}$ Zhifei Xu, ${ }^{2}$ Jun Ma, ${ }^{3}$ Xiaoxia Peng, ${ }^{4}$ Yongping Pan, ${ }^{5}$ \\ Xiaoyan Yan, ${ }^{6}$ Guixiang Wang, ${ }^{1}$ Yunxiao Wu, ${ }^{7}$ Li Zheng, ${ }^{1}$ Jiangnan Du, \\ Wentong Ge, ${ }^{1}$ Jie Zhang, ${ }^{1}$ Yamei Zhang, ${ }^{1}$ Xin $\mathrm{Ni}^{1,7}$
}

To cite: Li X, Tai J, Xu Z, et al. Systematic investigation of childhood sleep-disordered breathing (SDB) in Beijing: validation of survey methodology. BMJ Open 2018;8:e021097. doi:10.1136/ bmjopen-2017-021097

- Prepublication history for this paper is available online. To view these files, please visit the journal online (http://dx.doi org/10.1136/bmjopen-2017021097).

$\mathrm{XL}$ and $\mathrm{JT}$ contributed equally.

Received 14 January 2018 Revised 22 May 2018 Accepted 11 June 2018
Check for updates

(C) Author(s) (or their employer(s)) 2018. Re-use permitted under CC BY-NC. No commercial re-use. See rights and permissions. Published by BMJ.

For numbered affiliations see end of article.

Correspondence to

Professor Xin Ni;

nixin@bch.com.cn

\section{ABSTRACT}

Objective To systematically investigate and validate the survey methodology for the epidemiological study of childhood sleep-disordered breathing (SDB) in mainland China using the Mandarin version of the Pediatric Sleep Questionnaire-Sleep-Related Breathing Disorder (PSQSRBD).

Design A cross-sectional study using randomised, stratified, multistage, cluster sampling method.

Setting A total of 11 kindergartens, 7 primary schools and 8 middle schools from 7 districts of Beijing, China.

Participants A total of 9198 children with valid questionnaires (4736 boys and 4462 girls; age range 3.0-14.4 years) were included.

Primary and secondary outcome measures Data on sociodemographic characteristics and PSQ-SRBD were collected. The score on PSQ-SRBD and the included factors were calculated with the effective data after data cleaning. Logistic regression and factor analysis with the principal components method were used to evaluate the validity of the questionnaire; reliability was assessed by retesting $5 \%$ of the respondents after $2 \pm 4$ weeks of the initial test, and the intraclass correlation coefficient was calculated.

Results The effective response rate of $80.54 \%$ matched the sociodemographic characteristics of the respondents with respect to age group ratio and sex ratio in Beijing. With regard to construct validity of the PSQ-SRBD, the item score, except that of 'delayed growth', was highly correlated to the SRBD score as assessed by the logistic regression model. The exploratory factor analysis displayed a credible construct validity, with majority of the items grouped as the original dimensions. The testretest reliability coefficient of each dimension's score ranged from 0.758 to 0.901 , with an SRBD score of 0.730 indicating significant retest reliability.

Conclusions This study conducted and validated a successful survey methodology for investigation of childhood SDB in Beijing, China. The questionnaire demonstrated credible construct validity and retest reliability, thereby supporting the applicability and generalisability of the PSQ-SRBD in a large epidemiological survey of childhood SDB in China.
Strengths and limitations of this study

- This study focused on a rigorous methodology evaluation for the epidemiological survey of childhood sleep-disordered breathing in Beijing, China.

- The randomised, stratified, multistage, cluster sampling methodology of this cross-sectional study ensured accurate representation of the sample.

- For the first time, the Mandarin version of the Pediatric Sleep Questionnaire-Sleep-Related Breathing Disorder was used and validated in a large epidemiological survey in mainland China.

- Owing to the stringent sampling, the children involved in this survey represented only the Beijing population rather than the nationwide population; thus, comprehensive data on Chinese children should be obtained by a national multicentre investigation in the future.

\section{BACKGROUND}

Sleep-disordered breathing (SDB) is characterised by prolonged partial upper airway obstruction and/or intermittent complete pharyngeal obstruction that disrupts the normal ventilation during sleep. It ranges in severity from primary snoring to obstructive sleep apnoea syndrome (OSAS) ${ }^{1-4}$ If unrecognised and untreated, it causes severe complications that include excessive daytime sleepiness, behavioural abnormalities, learning disabilities, growth retardation, neurocognitive consequences, metabolic dysregulation, facial and dental morphometry, and increased risk of hypertension or cardiovascular events, which eventually negatively affect quality of life in the long term. ${ }^{5-7}$

The available epidemiological data on SDB in children are limited. The reported estimated prevalence of primary snoring in children varied from $8 \%$ to $27 \%$ and that of OSAS from $1 \%$ to $5 \% .{ }^{58}$ This wide range was 
mainly related to the diversity of questionnaires, small sample size, population subsets or races in different regions, broad age range, and lack of comprehensive systematic investigation or standard methodology evaluation in sampling approaches. ${ }^{59}$ In addition, there is limited awareness of epidemiological occurrences in children in mainland China. As a currently available diagnostic instrument and epidemiological tool, whether the Pediatric Sleep Questionnaire-Sleep-Related Breathing Disorder (PSQ-SRBD) is applicable in a large-scale epidemiological investigation among Chinese children is yet to be elucidated.

The present study reported the detailed sampling method and the methodological validation of a systematic investigation for childhood SDB. The goal was to systematically investigate and validate the survey methodology for the epidemiological study of childhood SDB in mainland China based on the PSQ-SRBD.

\section{METHODS}

\section{Design}

The present study used a cross-sectional, randomised, stratified, multistage, cluster sampling methodology. It primarily focused on the validation of the survey methodology, thereby laying the foundation for follow-up approaches; moreover, data on SDB prevalence among Chinese children will be reported subsequently in future reports.

\section{Setting and sampling}

According to the statistical formula, $\mathrm{n}=\frac{Z_{\alpha / 2}^{2} p(1-p)}{\delta^{2}}$ (where $\mathrm{n}, p$ and $\delta$ are sample size, positive rate and acceptable error, respectively), assuming a $4.8 \%$ prevalence of OSAS in children, ${ }^{10}$ significance at $\alpha=0.05$ with $\mathrm{Z}_{\alpha / 2}$ of 1.96 and acceptable error at $0.1 \mathrm{p}$, the sample size was calculated as 7619 . Allowing for a $20 \%$ non-response rate, the final intended sample size was set as 9600 .

The present study was conducted in Beijing, a city divided into 16 districts classified into 4 functional regions, namely the Capital Core Region, the Urban Developed Region, the Urban New Region and the Ecological Region (figure 1). Based on the proportion of children in each functional region $(0.097,0.451$, 0.331 and 0.121 , respectively), ${ }^{11}$ the regional sample size was determined as 930, 4330, 3178 and 1162, respectively. Half of the districts in each region were subjected to random sampling. However, based on the compliance and population size of each district, seven districts were randomly selected (district sampled but refused to participate was not included), and the sample size of each selected district was calculated by the population ratio. ${ }^{11}$ The respondents were recruited from kindergartens, primary schools and middle schools, encompassing the age group 3-14 years old, comprehensively. Based on the sample size of each age group and school scale, the selection of the school among the same educational

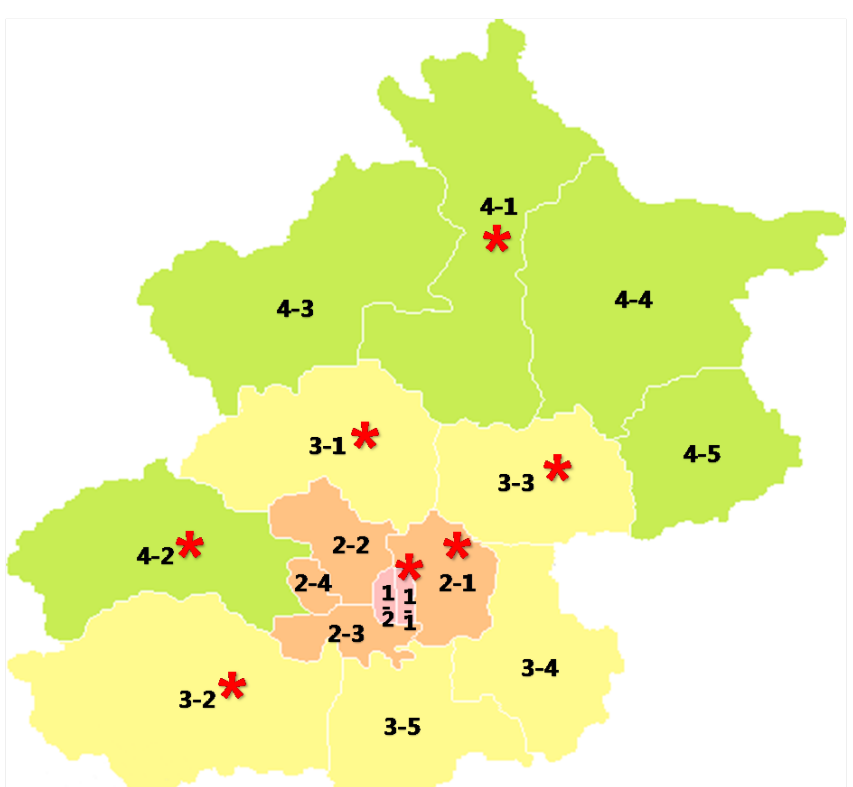

\begin{tabular}{|c|c|c|}
\hline \multicolumn{3}{|c|}{ Beijing regions and affiliated districts } \\
\hline Regions & 1 the Capital Core Region (pink) & $\begin{array}{l}2 \text { the Urban Developed Region } \\
\text { (orange) }\end{array}$ \\
\hline \multirow{4}{*}{ Districts } & 1-1 Dongcheng District * & 2-1 Chaoyang District* \\
\hline & 1-2 Xicheng District & 2-2 Haidian District \\
\hline & & 2-3 Fengtai District \\
\hline & & 2-4 Shijingshan District \\
\hline \multirow[t]{3}{*}{ Regions } & 3 the Urban New Region (yellow) & 4 the Ecological Region (green): \\
\hline & 3-1 Changping District * & 4-1 Huairou District * \\
\hline & 3-2 Fangshan District* & 4-2 Mentougou District * \\
\hline \multirow[t]{3}{*}{ Districts } & 3-3 Shunyi District* & 4-3 Yanqing District \\
\hline & 3-4 Tongzhou District & 4-4 Miyun District \\
\hline & 3-5 Daxing District & 4-5 Pinggu District \\
\hline \multicolumn{3}{|c|}{$\begin{array}{l}\text { The four functional regions were numbered as } 1 \text { to } 4 \text {, in order from the city centre } \\
\text { to the suburbs. }\end{array}$} \\
\hline \multicolumn{3}{|c|}{ The districts belonging to differents regions were numbered in alphabetical order. } \\
\hline
\end{tabular}

Figure 1 Map of Beijing districts. Districts with '*' indicate the sampling areas. The colours and numbers marked the functional regions and affiliated districts.

institutions was based on computer-generated random numbers, and if the selected school declined to participate the next randomly selected school was invited. The detailed sampling strategy is illustrated in figure 2. A total of 11 kindergartens, 7 primary schools and 8 middle schools from 7 districts of Beijing were selected randomly. The classes in each grade were sampled as a cluster by the random method described above, from which eligible children and their guardians were invited to participate in the survey.

\section{Patient and public involvement}

Teachers from child healthcare and school doctors were involved in the design of the survey by giving suggestions on organising field investigations. Children's sleep information and questionnaire scores were given as feedback to the sampling schools. Children or guardians interested in the results were advised to contact the school doctors for detailed information. The knowledge or results gained 


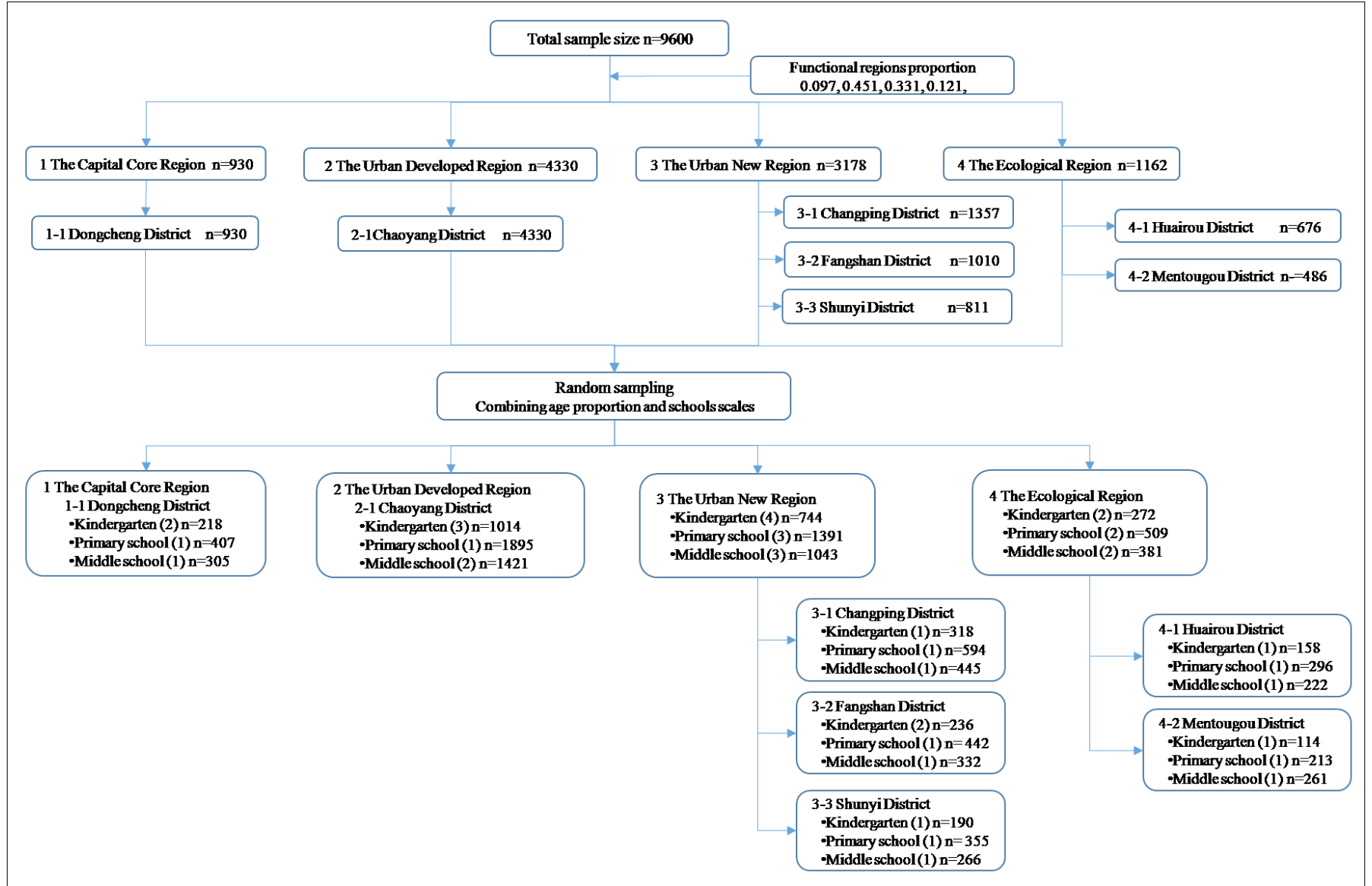

Figure 2 Sampling strategy. ' $n$ ' indicates the planning sample size of the different regions and districts. The number in parentheses indicates the number of schools randomly selected.

from this project will be disseminated to the public at different medical meetings and professional seminars in China.

\section{Questionnaire}

The guardians of all respondents were asked to complete the general information questionnaire and the PSQ-SRBD in Mandarin within 20-30 min. The questionnaires were self-administered by guardians, and the survey facilitators were available to clarify any concerns. Quality was audited to ensure that all questionnaires were completed appropriately. A valid questionnaire was the one that had been audited and signed by a supervisor.

The general information questionnaire was used to collect self-reported demographic data on age, sex, marital status, education, sleep habits, current physical status, medical history and family history. The PSQ-SRBD consisted of 22 items clustered in four dimensions or factors-'Breathing', 'Sleepiness', 'Behavior' and 'Others' - which evaluated childhood SRBD symptoms over the previous 6 months. The questions were simple and concise, with a yes/no/don't know response format instead of Likert responses. Then, the scale scores were calculated as the proportion of questions was answered affirmatively, ranging from 0 to 1 , with higher scores indicating greater severity. ${ }^{12-14}$ The occasional missing answers or the 'don't know' responses were discounted from the denominator while calculating the proportions.

As the main survey tool, we completed the introduction and localisation of the simplified Chinese (Mandarin) version of the PSQ for this large-scale survey. ${ }^{15}$ In our previous study, a total of 235 children (145 in the OSAS group vs 90 in the control group) aged 3-16 years were asked to complete the simplified Chinese version of the PSQ in paper format, which was based on the translation and retroversion from the PSQ-SRBD. Confirmatory factor analysis indicated that maximal items belonged to the factors with load coefficient $\geq 0.5$. The Cronbach's alpha coefficients were 0.703 (SRBD score), 0.767 (breathing factor), 0.849 (sleepiness factor) and 0.689 (behaviour factor). The test-retest intraclass correlation coefficient (ICC) reliability was 0.986 (SRBD score), 0.991 (breathing factor), 0.727 (sleepiness factor) and 0.870 (behaviour factor), with $\mathrm{p}<0.05$. In the receiver operating characteristic curve, the area under the curve was 0.922 , with $\mathrm{p}<0.05$, and the cut-off value of the SRBD score was 0.30 , with sensitivity, specificity, positive predictive value and negative predictive value of $0.776,0.867$, 0.868 and 0.774 , respectively. These results suggested that 
the PSQ-SRBD was suitable for use in Chinese children, with satisfactory reliability and validity along with acceptable sensitivity and specificity in screening children with probable OSAS.

\section{Data processing}

Coding and double entry of questionnaire responses were carried out by two independent professional dataentry staff. EpiData V.3.1 software (EpiData Foundation, Odense, Denmark $)^{16}$ was used to verify consistency between the two sets of data entries for data quality; discrepancies were resolved by the third staff personnel, who reviewed the original paper questionnaire and confirmed the information.

In the data cleaning stage, JMP for Windows V.11.0.0 (Statistical Discovery from SAS Institute, USA) was used to explore the missing values and outliers and eliminate duplicate records. The multivariate singular value decomposition analysis was used to fill the missing values for continuous demographic data. For the questionnaire data, the mean value of the same variable was used to input the missing values where at least $50 \%$ of the items in the PSQ were completed, failing which the data of the respondent were excluded from the analysis. As the outliers were almost focused on continuous data such as height and weight, quantiles were used to detect the outliers by setting the tail quantile as 0.1 .

SPSS V.20 software for Windows V.13.0 was used for data analysis. All hypothesis tests were two-sided, and a two-tailed $p$ value $\leq 0.05$ indicated statistical significance. For the construct validity of the PSQ-SRBD, logistic regression was used to measure the strength of the association between items and the suspected SDB, and factor analysis by the principal components method with varimax rotation was employed for the exploratory validation of the factor structure. Test-retest reliability was used to measure the stability of the questionnaire under different conditions with the same respondent. In this study, reliability was assessed by retesting $5 \%$ of the respondents after $2 \pm 4$ weeks of the initial test, and the ICC was calculated.

\section{RESULTS}

\section{Response rate}

Seven districts were randomly sampled: Dongcheng District from the Capital Core Region, Chaoyang District from the Urban Developed Region, Fangshan, Changping and Shunyi Districts from the Urban New Region, and Mentougou and Huairou Districts from the Ecological Region (figure 1). The schools were randomly selected from districts, and finally 11 kindergartens, 7 primary schools and 8 middle schools were included in the present study.

A total of 11420 questionnaires were distributed, and 10743 were completed, with a response rate of $94.07 \%$, overfulfilling the expected sample size of 9600 . Due to incompleteness and false information, 1545 questionnaires were excluded, and finally a total of 9198 valid questionnaires were included in the analysis after quality audit and data cleaning, with an effective rate of $80.54 \%$ (figure 3). Of the 460 respondents randomly selected for test-retest, 324 were available for reinterview (response rate of $70.43 \%$ ). Thirty-five questionnaires were rejected

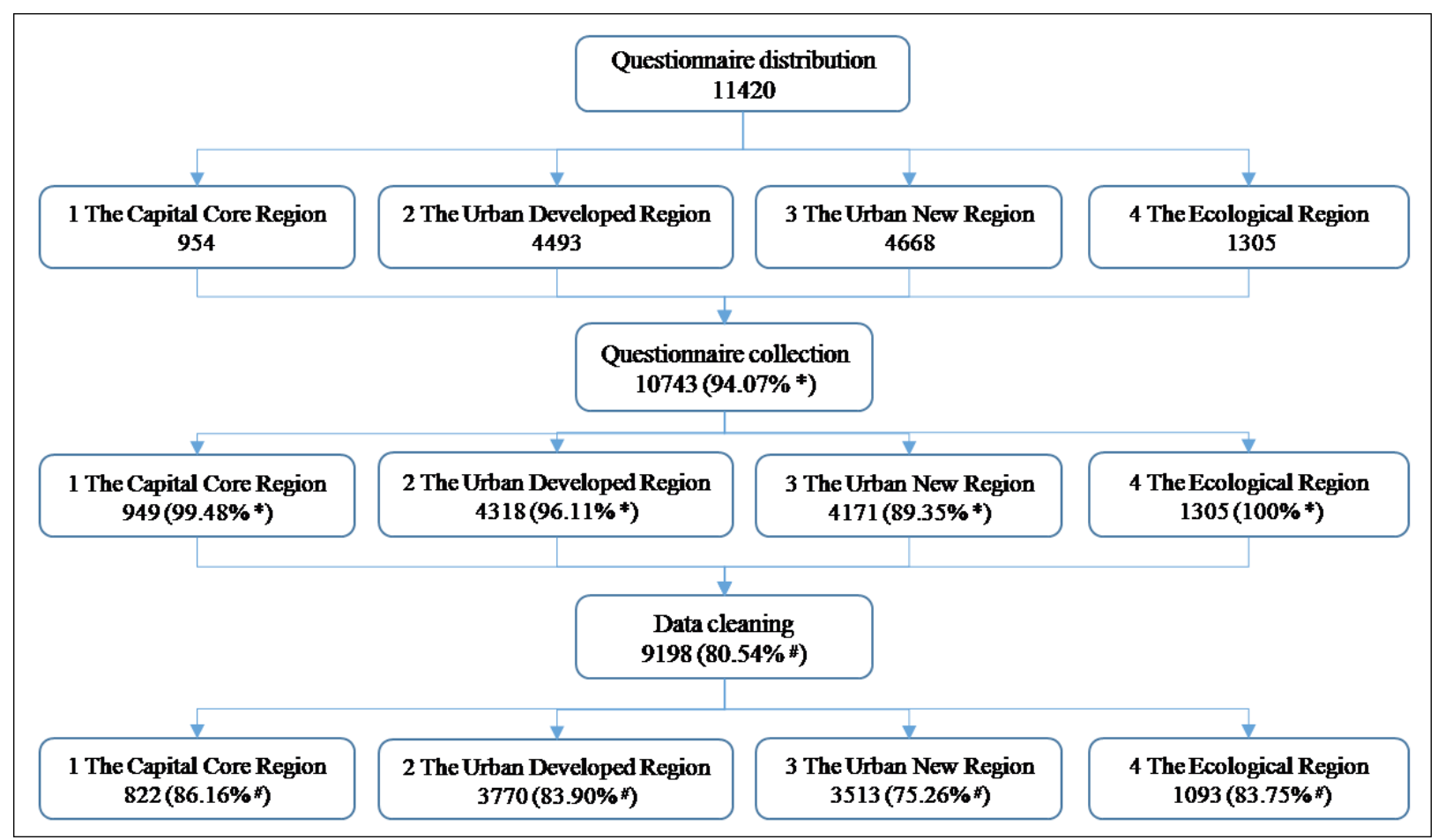

Figure 3 Response rate and effective rate. *Response rate=collection number/distribution number. \#Effective rate=effective number/collection number. Valid number was the number of valid questionnaires after data cleaning. 

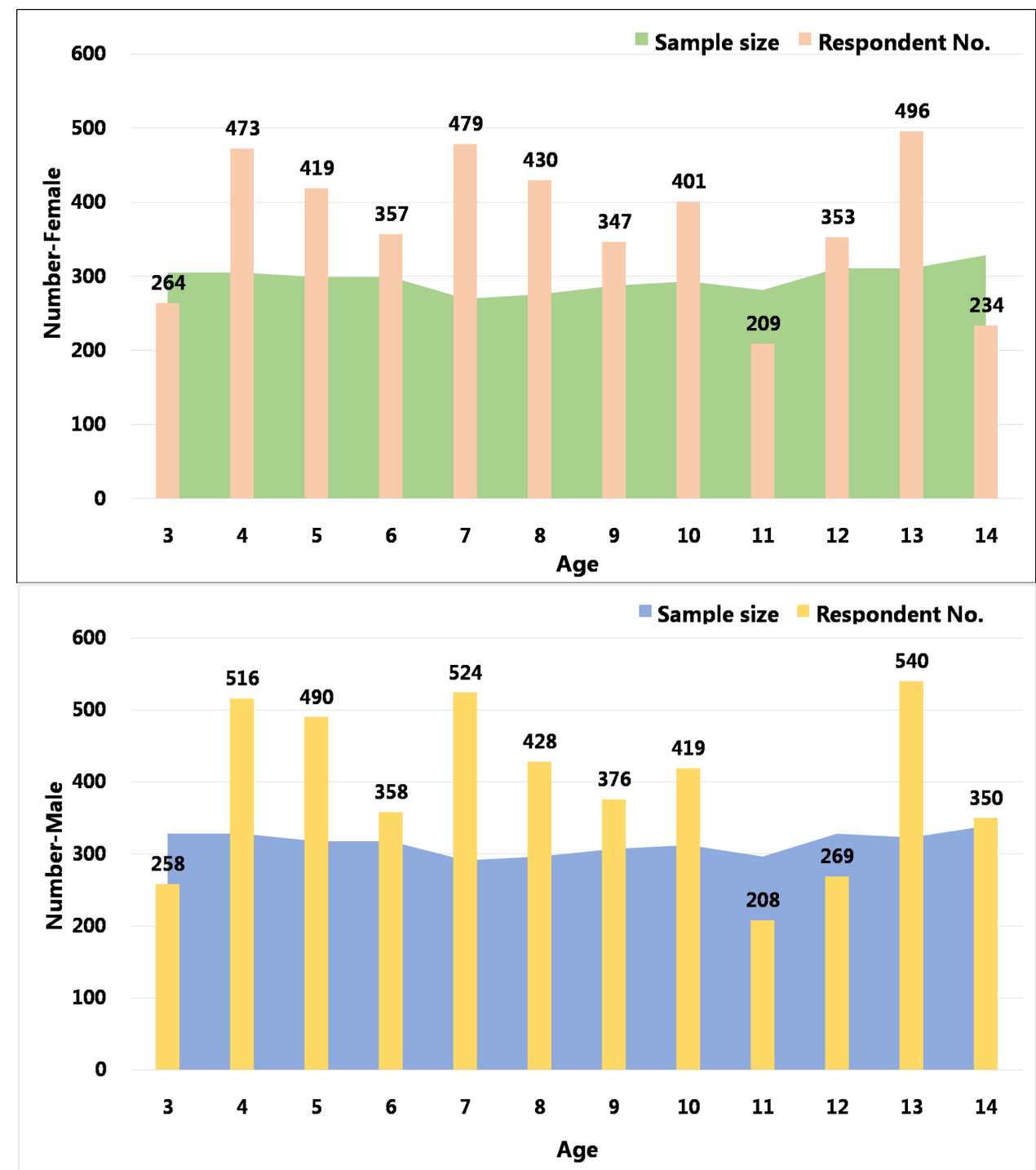

Figure 4 Age distribution of the sample and male and female respondents. Columns represent the effective number of questionnaires in different age groups of children in both sexes. The background colour indicates the planned sample size (total sample size - the estimated $20 \%$ unresponsive number) of the different age groups.

as they were not completed according to the study protocol, leaving only 289 questionnaires for inclusion in the retest analysis, with an effective rate of $62.83 \%$.

\section{Respondents}

The average age of the respondents was $8.8 \pm 3.8$ (range $3.0-14.4$ ) years, comprising 4736 boys and 4462 girls. The number of effective respondents from each age group is shown in figure 4 , with the planned sample size (total sample size - the estimated $20 \%$ unresponsive number) in the background. The average body mass index (BMI) was 18.45 (range $11.30-39$ ) $\mathrm{kg} / \mathrm{m}^{2}$. All demographic and baseline data categorised by age group are shown in table 1 .

\section{Validity}

The OR of logistic regression models ranged from 27.018 to 2.324, explaining the correlation between each question item, except that of the 'delayed growth', and the SRBD score, with a statistically significant difference $(\mathrm{p}<0.001)$ (table 2$)$. The exploratory factor analysis was deemed suitable for verifying the predicted factor structure with a Kaiser-Meyer-Olkin (KMO) value of 0.788 and Bartlett's ball type test $(\mathrm{p}<0.001)$. Combining the scree plot and the actual role of each item, five factors were extracted by principal component analysis and varimax rotation via with a cumulative rate of $61.8 \%$. The credible construct validity was demonstrated with $\geq 0.5$ loading value for each item, and most of the items were regrouped as the original dimensions, except A24, A25 and B7, which correlated more strongly with the new factor named 'morning' than the original factor 'breathing'. In addition, two items, $\mathrm{B} 1$ and $\mathrm{B} 6$, from the original 'others' were distributed into the new factors 'morning' and 'sleepiness', respectively.

\section{Reliability}

The test-retest reliability coefficient ICC of the SRBD score was 0.730 , with 0.863 in breathing, 0.901 in 
Table 1 Demographic information of the respondents

\begin{tabular}{lcccc} 
Age group (years) & $\mathbf{3 - 6}$ & $\mathbf{7 - 1 0}$ & $\mathbf{1 1 - 1 4}$ & Total \\
\hline $\mathrm{n}(\%)^{*}$ & $3153(34.28)$ & $3408(37.05)$ & $2637(28.67)$ & 9198 \\
Gender (male:female) $\dagger$ & 1.07 & 1.05 & 1.06 & 1.06 \\
Weight $(\mathrm{kg}) \ddagger$ & $20.89 \pm 11.71$ & $34.04 \pm 11.53$ & $50.52 \pm 12.05$ & $25.08 \pm 11.68$ \\
Height $(\mathrm{cm}) \ddagger$ & $111.83 \pm 16.54$ & $137.00 \pm 16.39$ & $156.4 \pm 17.05$ & $118.79 \pm 16.52$ \\
Body mass index $\left(\mathrm{kg} / \mathrm{m}^{2}\right) \ddagger$ & $16.62 \pm 4.35$ & $18.10 \pm 4.30$ & $21.1 \pm 4.35$ & $18.45 \pm 4.34$
\end{tabular}

*Number of respondents (proportion in total number).

†Male to female ratio.

$\ddagger$ Mean \pm SD.

sleepiness, 0.740 in behaviour and 0.758 in others, indicating significance $(\mathrm{p}<0.001)$.

\section{DISCUSSION}

Along with the cancellation of one-child policy and the approaching second-child era in China, the number of Chinese children will reach a new peak of growth. With increasing attention on childhood sleep health, vague and incomplete epidemic statistics resulted in a growing neglect of childhood SDB or OSAS, thereby contributing to the development of the most debilitating and cost-ineffective chronic diseases in the future. In addition, it will impose a significant social and economic burden in the children healthcare system nationwide. 571718

Although epidemiological data have been reported in the West, ${ }^{519}$ only a few studies have been carried out

Table 2 Results of logistic regression and factor analysis of the PSQ-SRDB

\begin{tabular}{|c|c|c|c|c|c|}
\hline \multirow[b]{2}{*}{ Symptom category } & \multirow[b]{2}{*}{ Item } & \multicolumn{2}{|c|}{ Logistic regression* } & \multicolumn{2}{|c|}{ Factor analysis } \\
\hline & & OR & P values & New factor & Loading \\
\hline \multirow[t]{7}{*}{ Factor 1: breathing } & A2: snores more than half the time & 15.956 & $<0.001$ & Breathing & 0.596 \\
\hline & A4: snores loudly & 14.027 & $<0.001$ & Breathing & 0.707 \\
\hline & A5: heavy breathing & 10.628 & $<0.001$ & Breathing & 0.716 \\
\hline & A7: observed apnoeas & 11.325 & $<0.001$ & Breathing & 0.420 \\
\hline & A24: mouth open during day & 6.568 & $<0.001$ & Morning & 0.496 \\
\hline & A25: dry mouth on awakening & 4.73 & $<0.001$ & Morning & 0.741 \\
\hline & B7: morning headache & 6.453 & $<0.001$ & Morning & 0.673 \\
\hline Factor 2: sleepiness & B2: problem with sleepiness & 6.849 & $<0.001$ & Sleepiness & 0.809 \\
\hline \multirow{5}{*}{ Factor 3: behaviour } & C5: difficulty in organising & 6.235 & $<0.001$ & Behaviour & 0.475 \\
\hline & C8: easily distracted & 7.428 & $<0.001$ & Behaviour & 0.596 \\
\hline & C10: fidgets & 11.173 & $<0.001$ & Behaviour & 0.617 \\
\hline & C14: on the go & 7.234 & $<0.001$ & Behaviour & 0.666 \\
\hline & C18: interrupts & 7.426 & $<0.001$ & Behaviour & 0.654 \\
\hline \multirow{4}{*}{$\begin{array}{l}\text { Factor 4: other } \\
\text { symptoms }\end{array}$} & A32: nocturnal enuresis & 2.761 & $<0.001$ & Others & 0.660 \\
\hline & B1: unrefreshed in morning & 11.942 & $<0.001$ & Morning & 0.461 \\
\hline & B6: hard to wake up & 7.142 & $<0.001$ & Sleepiness & 0.337 \\
\hline & B9: delayed growth & - & 0.998 & Others & 0.199 \\
\hline
\end{tabular}

The number of the items was arranged in accordance with the original questionnaire. ${ }^{12}$

*Logistic regression was used to measure the strength of association between the items and the suspected SDB.

†Factor analysis was conducted by the principal components method with varimax rotation.

PSQ-SRDB, Pediatric Sleep Questionnaire-Sleep-Related Breathing Disorder; SDB, sleep-disordered breathing. 
in Asia in recent years, except the study on Japanese preschool children with an estimated OSAS prevalence of $7.3 \%$ and $12.8 \%$ (according to the International classification of sleep disorders-second edition (ICSD-2) and International classification of sleep disorders-third edition (ICSD-3) criteria, respectively), ${ }^{20}$ and the study from Hong Kong with a prevalence rate of childhood OSAS varying from $4.8 \%$ to $40.3 \%$, as measured by different cut-offs (Obstructive Apnea Hypopnea Index $\geq 1, \geq 1.5, \geq 3$ and $\geq 5$, and Obstructive Apnea Index $\geq 5$ ). Since prevalence has not yet been reported in mainland China, a reliable large-scale epidemiological study of childhood SDB is an urgent requisite. Based on the SDB epidemic investigation in children in other countries, we found that the differences in prevalence rates resulted from differences in gender, BMI, race, region ${ }^{2122}$ and the limited availability of Polysomnography (PSG), ${ }^{12} 2324$ and also from differences in survey methodology including sample size, sampling methods and screening questionnaires. These results increased the focus on the methodological instructions and the potential utility of the PSQ-SRBD as a screening tool.

Beijing was chosen as the single-centre survey city owing to its dense population. By the end of 2010, the children population of Beijing (0-19 years old) had increased up to 2.64 million, accounting for $0.86 \%$ of that of the country (The Sixth Population Census in China, 2010). ${ }^{11}$ With the high response and effective rates, the distribution of sample age groups was relatively uniform and the ratio of 3-6 years old group, 7-10 years old group and 11-14 years old group was in accordance with the census data (1:1.09:0.85 vs 1:1.01:0.93). ${ }^{11}$ The sample proportion of boys and girls was consistent with the census results in Beijing (1.06:1) and similar to the Chinese national data of 1.05:1 in children aged 3-16years old. ${ }^{11}$ Thus, the sample satisfactorily represented the population of children in Beijing. Although Beijing is a multipopulation city, childhood sleep habits and SDB-related symptoms of different cities may be affected by regions. Therefore, whether the sample population is representative of other cities in China and further multicentre survey will be needed is yet to be elucidated.

The PSQ-SRBD was designed as a primary screening instrument that demonstrated adequate reliability and validity. A review of the available instruments as paediatric sleep diagnostic or epidemiological tools by Spruyt and Gozal $^{25}$ recommended the PSQ-SRBD as an optimal SRBD diagnostic tool based on adequate psychometric properties. Importantly, the PSQ-SRBD was also recommended as a screening tool by the guidelines of the American Academy of Pediatrics based on level IV evidence. The items of PSQ-SRBD focused on three prominent symptom complexes: snoring, excessive daytime sleepiness and inattentive/hyperactive behaviour, which encompassed the clinical manifestations in the latest criteria of the ICSD$3 .{ }^{2627}$ Since SDB affects children of preschool and school age, ${ }^{28}$ with the peak prevalence at $2-8$ years due to the high incidence of tonsillar and adenoidal hypertrophy, ${ }^{29}$ we preferred to sample children $>3$ years of age. Moreover, Chervin $e t a l^{12}$ focused on the age group 2-18years old in the original PSQ research, and the Spanish ${ }^{30}$ and Taiwan versions of the $\mathrm{PSQ}^{31}$ on children aged 6-16years old, corresponding to the age range used in the present study.

On the questionnaire, the breathing symptoms were demonstrated to be highly relevant with the SRBD score; this phenomenon might be attributed to the high score proportion, consistent with the results of other PSQ versions. ${ }^{123031}$ Furthermore, Chinese parents were more likely to focus on respiratory symptoms while the related items were rendered with less ambiguous indications and low abandon rate, which was in agreement with clinical experience and obstructive pathophysiological mechanisms. Other items, except 'B9: delayed growth', were also shown to be apparently correlated with the SRBD score, although with a slightly weaker association than that of the 'breathing' items. Thus, 'B9 delayed growth' seemed to be incompatible with the whole scale in this survey, which might originate from the lack of understanding of 'delayed growth' among Chinese parents, neglect of concerns regarding growth and development, or reluctance to acknowledge the delayed growth of their children. ${ }^{32}$ Therefore, the correlation between the dimensional score and SRBD score was also affected adversely. The exploratory factor analysis extracted a novel factor based on the four items of symptoms after waking up in the morning. However, as a direct result of the nocturnal breathing disorders, morning discomfort and night respiratory symptoms are inseparable. By comparing the regression coefficients, respiratory problems were more relevant to the primary breathing factor than the morning discomfort items. The retest reliability of the PSQ-SRBD was satisfactory, reflecting the stability of items and the consistency of the questionnaire, with small measurement errors due to different times and situations.

In summary, according to the present situation of children in China, the cluster random sampling method with the class as a unit is effective and worthy of reference for other epidemiological investigations. On the other hand, the first large-scale application of the PSQ as a screening questionnaire in mainland China is also satisfactory. These characteristics suggest that doctors at proletarian medical institutions can use the questionnaire when screening children with a suspected diagnosis of sleep breathing disorder. The items related to upper airway obstruction symptoms should be under intensive clinical focus. Nevertheless, the present study has several limitations. First, the children in the age group 3-14 years were involved in the investigation, while the graduating class students of primary and middle schools were not included, which resulted in a lack of the respondents' number in age of 11 year-old and 14 year-old and the unbalance among the number in all ages. Second, the Beijing children in this survey did not represent those from the whole country or other cities. Third, the short 
retest period might distort the reliability analysis, wherein the respondents remember their previous responses. Fourth, the sampling methodology was unable to sample children of migrant workers, who constitute a significant proportion of the children population in Beijing, as they remain officially registered in their place of origin.

\section{CONCLUSIONS}

The methodology employed for this large epidemiological study of childhood SDB across Beijing was valid and credible. The sampling and administration techniques contributed substantially to the success of the study, which could be used for further learning and reference. The PSQ-SRBD was demonstrated as an acceptable screening tool with applicability and generalisability.

\section{Author affiliations}

${ }^{1}$ Department of Otolaryngology, Head and Neck Surgery, Beijing Children's Hospital, Capital Medical University, Beijing, China

${ }^{2}$ Respiratory Department, Beijing Children's Hospital, Capital Medical University, Beijing, China

${ }^{3}$ Institute of Child and Adolescent Health, Peking University Health Science Center, Beijing, China

${ }^{4}$ Center for Clinical Epidemiology and Evidence-based Medicine, Beijing Children's Hospital, Capital Medical University, Beijing, China

${ }^{5}$ Health Care Center of Primary and Middle School of Dongcheng District, Beijing, China

${ }^{6}$ Clinical Institute of Peking University, Beijing, China

${ }^{7}$ Beijing Key Laboratory for Pediatric Diseases of Otolaryngology, Head and Neck Surgery, Beijing Pediatric Research Institute, Beijing Children's Hospital, Capital Medical University, Beijing, China

Acknowledgements The authors would first like to express their gratitude to the children and their guardians for participation in the survey. The authors would like to thank the Beijing Municipal Science and Technology Project and the Beijing Municipal Administration of Hospitals Clinical Technology Innovation Project for financial support. The authors greatly acknowledge the cooperation of the team of otolaryngologists, evidence-based medicine specialists, sleep medicine specialists, child healthcare teachers, school doctors and other medical personnel, who collected the data for this project. The authors would like to thank the 26 schools from the 7 districts of Beijing for the cooperation and arrangement of the survey.

Contributors XN served as the director of the survey. XN, JT, ZX, JM and XP were responsible for the design of the study and sampling. XL and GW were responsible for the on-site training and supervision. YW, LZ and JD were responsible for the survey arrangements.YP and $X Y$ completed the quality control of the questionnaries. $\mathrm{JZ}, \mathrm{YZ}$ and WG were responsible for data management. XLand JT analysed the data and wrote the first draft of the paper. All authors contributed to the final manuscript. $\mathrm{XN}$ is the corresponding author and is responsible for the overall content as the guarantor.

Funding This work was supported by Beijing Municipal Science and Technology Project grant (Z161100000116050 and Z161100003216212) and Beijing Municipal Administration of Hospitals Clinical Technology Innovation Project grant (XMLX201701). This study was also supported by the Beijing Children's Hospital, Capital Medical University, and the Institute of Child and Adolescent Health of Peking University.

Competing interests None declared.

Patient consent Parental/guardian consent obtained.

Ethics approval Ethical approval was granted by the Ethics Committee of Beijing Children's Hospital (BCH 2013-76).

Provenance and peer review Not commissioned; peer reviewed for ethical and funding approval prior to submission.

Data sharing statement № additional data are available.
Open access This is an open access article distributed in accordance with the Creative Commons Attribution Non Commercial (CC BY-NC 4.0) license, which permits others to distribute, remix, adapt, build upon this work non-commercially, and license their derivative works on different terms, provided the original work is properly cited, appropriate credit is given, any changes made indicated, and the use is non-commercial. See: http://creativecommons.org/licenses/by-nc/4.0/.

\section{REFERENCES}

1. Venekamp RP, Hearne BJ, Chandrasekharan D, et al. Tonsillectomy or adenotonsillectomy versus non-surgical management for obstructive sleep-disordered breathing in children. Cochrane Database Syst Rev 2015;114:D11165

2. Schwengel DA, Dalesio NM, Stierer TL. Pediatric obstructive sleep apnea. Anesthesiol Clin 2014;32:237-61.

3. Katz ES, D'Ambrosio CM. Pathophysiology of pediatric obstructive sleep apnea. Proc Am Thorac Soc 2008;5:253-62.

4. Marcus CL. Sleep-disordered breathing in children. Am J Respir Crit Care Med 2001;164:16-30.

5. Marcus CL, Brooks LJ, Draper KA, et al. Diagnosis and management of childhood obstructive sleep apnea syndrome. Pediatrics 2012;130:576-84.

6. Tseng P-H, Lee P-L, Hsu W-C, et al. A Higher Proportion of Metabolic Syndrome in Chinese subjects with sleep-disordered breathing: a case-control study based on electrocardiogram-derived sleep analysis. PLOS One 2017;12:e0169394.

7. Farrell PC, Richards G. Recognition and treatment of sleepdisordered breathing: an important component of chronic disease management. J Transl Med 2017;15:114.

8. Shine NP, Coates HL, Lannigan FJ. Obstructive sleep apnea, morbid obesity, and adenotonsillar surgery: a review of the literature. Int $J$ Pediatr Otorhinolaryngol 2005;69:1475-82.

9. Berry RB, Budhiraja R, Gottlieb DJ, et al. Rules for scoring respiratory events in sleep: update of the 2007 AASM Manual for the Scoring of Sleep and Associated Events. Journal of Clinical Sleep Medicine 2012;8:597-619.

10. Li AM, So HK, Au CT, et al. Epidemiology of obstructive sleep apnoea syndrome in Chinese children: a two-phase community study. Thorax 2010;65:991-7.

11. The Sixth Population Census in China [EB/OL]. http://www.stats.gov. $\mathrm{cn} / \mathrm{tjsj} / \mathrm{pcsj} / \mathrm{rkpc} / 6 \mathrm{rp} / \mathrm{indexce}$.htm

12. Chervin RD, Hedger K, Dillon JE, et al. Pediatric sleep questionnaire (PSQ): validity and reliability of scales for sleep-disordered breathing, snoring, sleepiness, and behavioral problems. Sleep Med 2000;1:21-32.

13. Marcus CL, Brooks LJ, Draper KA, et al. Diagnosis and management of childhood obstructive sleep apnea syndrome. Pediatrics 2012;130:e714-55

14. Chervin RD, Weatherly RA, Garetz SL, et al. Pediatric sleep questionnaire: prediction of sleep apnea and outcomes. Arch Otolaryngol Head Neck Surg 2007;133:216-22.

15. Li XD, Tai J, Xu ZF, et al. [The validity and reliability of simplified Chinese version of the pediatric sleep questionnaire for screening children with obstructive sleep apnea syndrome in Beijing]. Zhonghua Er Bi Yan Hou Tou Jing Wai Ke Za Zhi 2016;51:812-8.

16. EpiData Software. Data management and basic statistical analysis system[EB/OL]. 2001. http://www.epidata.dk

17. Jennum P, Kjellberg J. Health, social and economical consequences of sleep-disordered breathing: a controlled national study. Thorax 2011;66:560-6.

18. D'Ambrosio C, Bowman T, Mohsenin V. Quality of life in patients with obstructive sleep apnea: effect of nasal continuous positive airway pressure--a prospective study. Chest 1999;115:123-9.

19. Bixler EO, Vgontzas AN, Lin HM, et al. Sleep disordered breathing in children in a general population sample: prevalence and risk factors. Sleep 2009;32:731-6.

20. Kitamura T, Miyazaki S, Kobayashi R, et al. Obstructive sleep apnea in preschool-aged Japanese children - efficiency of screening using lateral neck radiography. Acta Otolaryngol 2016;136:606-12.

21. Rudnick EF, Walsh JS, Hampton MC, et al. Prevalence and ethnicity of sleep-disordered breathing and obesity in children. Otolaryngol Head Neck Surg 2007;137:878-82.

22. Redline S, Tishler PV, Schluchter M, et al. Risk factors for sleepdisordered breathing in children. Associations with obesity, race, and respiratory problems. Am J Respir Crit Care Med 1999;159(5 Pt 1):1527-32

23. Friedman NR, Perkins JN, McNair B, et al. Current practice patterns for sleep-disordered breathing in children. Laryngoscope 2013;123:1055-8. 
24. Pringle MB, Natesh BG, Buchanan EM. National UK survey on the assessment and surgical management of suspected paediatric obstructive sleep apnoea syndrome. Int J Pediatr Otorhinolaryngol 2013;77:1689-96.

25. Spruyt K, Gozal D. Pediatric sleep questionnaires as diagnostic or epidemiological tools: a review of currently available instruments. Sleep Med Rev 2011;15:19-32.

26. Sateia MJ. International classification of sleep disorders-third edition: highlights and modifications. Chest 2014;146:1387-94.

27. Medicine American Academy Of Sleep. International classification of sleep disorders. 3rd edn: Medicine American Academy Of Sleep, 2014.

28. Walter LM, Nixon GM, Davey MJ, et al. Differential effects of sleep disordered breathing on polysomnographic characteristics in preschool and school aged children. Sleep Med 2012;13:810-5.
29. DelRosso LM. Epidemiology and diagnosis of pediatric obstructive sleep Apnea. Curr Probl Pediatr Adolesc Health Care 2016;46:2-6.

30. Bertran K, Mesa T, Rosso K, et al. Diagnostic accuracy of the Spanish version of the pediatric sleep questionnaire for screening of obstructive sleep apnea in habitually snoring children. Sleep Med 2015;16:631-6.

31. Huang Y-S, Hwang F-M, Lin C-H, et al. Clinical manifestations of pediatric obstructive sleep apnea syndrome: clinical utility of the chinese-version obstructive sleep apnea questionaire-18. Psychiatry Clin Neurosci 2015;69:752-62.

32. Li SH, Jin XM, Shen XM, et al. [Development and psychometric properties of the Chinese version of Children's Sleep Habits Questionnaire]. Zhonghua Er Ke Za Zhi 2007;45:176-80. 